\title{
ENTREVISTA COM GEORGE MARTINE
}

\author{
Roberto Luiz do Carmo
}

Igor Cavallini Johansen

George Martine é um dos mais conhecidos pesquisadores que têm contribuído no Brasil e no exterior para o debate sobre População e Ambiente. Graduado em Artes e Ciências pela University of Ottawa, Canadá (1959), mestre em Sociologia pela Fordham University, Estados Unidos (1965) e Doutor em Demografia e Ecologia pela Brown University, Estados Unidos (1969), trabalha em temas como migração interna, população e desenvolvimento, desigualdade, pobreza, urbanização e sustentabilidade.

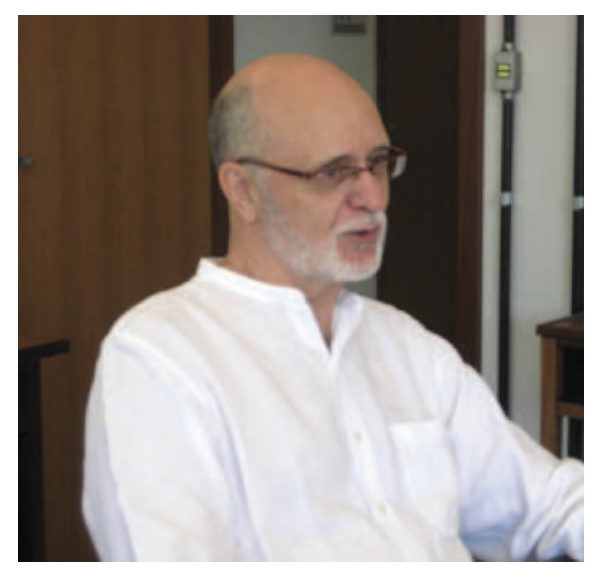

George Martine. Imagem: arquivo pessoal. 
Esta entrevista foi gentilmente concedida por George Martine através de e-mail. O texto abaixo apresenta as questões formuladas por Roberto Luiz do Carmo e Igor Cavallini Johansen e, em seguida, as respostas elaboradas pelo pesquisador e consultor George Martine.

Revista Idéias: Seria ótimo se você pudesse começar contando um pouco sobre a sua trajetória, desde local de origem, passando pela formação acadêmica e como se estabeleceu no Brasil.

George Martine: Nasci e morei no Canadá até os 23 anos, cheguei ao Brasil de araque e acabei ficando por fatalidade do destino. Era vagamente idealista (na época, usava-se!), tinha estudado várias coisas, mas não tinha conseguido me 'conectar'. Vim para trabalhar como voluntário num Centro que promovia a aculturação de estrangeiros chegando ao Brasil via programas de ajuda externa. Desembarquei no Galeão sem ter a mínima ideia do que me esperava. Mas tirei a sorte grande, pois esta experiência traçou o rumo da minha vida pessoal e profissional.

A instituiçãoem quecaí patrocinava palestrase discussõesque abriram minha cabeça para as complexidades do desenvolvimento e me motivaram a ir estudar sociologia e demografia nos EUA. Fiz minha dissertação de mestrado sobre a questão do engajamento político do cientista social e a do doutorado sobre migrações internas no Brasil. Logo em seguida, conduzi uma pesquisa sobre formação da família e marginalidade no Rio (publicada depois pelo Celade) e, já com família para sustentar, fui trabalhar na CEPAL em Santiago do Chile, onde fiquei até o golpe de Pinochet.

Querendo fugir daquele Chile, tive a sorte de ser convidado para voltar ao Brasil no contexto de um projeto ambicioso de desenvolvimento social da ONU durante a ditadura. Trabalhei inicialmente como assessor de um programa nacional de migrações internas sediado no Ministério do Interior (Minter). Este cargo me colocou em contato com muitos pesquisadores e técnicos pelo Brasil afora e daí surgiu até minha participação na criação da Associação Brasileira de Estudos Populacionais (ABEP). 
Quatro anos depois do retorno ao Brasil, assumi a coordenação da parte internacional deste mesmo projeto da ONU no CNRH/ IPEA, organismo que naquele tempo servia como o 'think tank' do governo para a área social.

Fiquei neste cargo até 1990 e tive a oportunidade de trabalhar em várias questões de proa como política social, emprego, desenvolvimento regional, política de população, política agrícola e colonização. O meu interesse na questão ambiental brotou desta confluência de interesses, particularmente ao analisar a forma como as políticas governamentais estavam afetando a região amazônica.

Ao deixar a ONU, participei com Donald Sawyer e Haroldo Torres na fundação de uma ONG (o Instituto Sociedade, População e Natureza - ISPN) onde trabalhei sobre as interfaces entre os temas de população, desenvolvimento e meio ambiente durante quatro anos. Em seguida, passei dois anos em Harvard como Senior Fellow no Centro de População e Desenvolvimento daquela universidade - minha única experiência 'acadêmica' pura. Depois, fui convidado a trabalhar com a equipe técnica interagencial do UNFPA para a América Latina e Caribe, primeiro como assessor em população e meio ambiente e, em seguida, como diretor desta equipe regional.

$\mathrm{Na}$ aposentadoria, retornei ao Brasil e assumi a presidência da ABEP (2005-2008). Neste período de suposta 'aposentadoria', tenho feito consultorias para vários organismos internacionais. Tive a oportunidade de trabalhar com muitos temas, mas sempre preferindo enfocar as questões que ligavam urbanização e meio ambiente.

Continuo mais interessado na aplicação política do conhecimento do que no avanço científico em si. Neste sentido, a minha maior oportunidade surgiu quando fui convidado a escrever o 'State of the World Population 2007' do UNFPA, resultando na publicação do livro "Unleashing the Potential of Urban Growth". Nesta publicação, eu pude sintetizar, de forma acessível para uma audiência ampla, uma série de ideias sobre as quais vínhamos trabalhando em relação ao processo da urbanização. Pelo fato de ser uma publicação com "a chancela da 
ONU", de ser distribuída em oito idiomas, e sobretudo de oferecer alguns argumentos pouco ortodoxos para a época, este trabalho teve uma repercussão que nunca teria tido se fosse escrito como livro acadêmico.

Desde então, tenho trabalhado em vários projetos sobre os mesmos temas - urbanização, pobreza, meio ambiente - com o International Institute for Environment and Development (IIED), e isto tem rendido alguns artigos e livros.

Revista Idéias: Você é um dos precursores dos estudos de População e Ambiente no Brasil. Quando essas questões começaram a ser sistematizadas no país, configurando-se como objeto de pesquisa e de política pública? Poderia citar quais eram as principais problemáticas discutidas naquele contexto inicial?

George Martine: Acho que a história dos estudos sobre população e meio ambiente no Brasil está muito bem relatada no excelente artigo de Marandola e Hogan, publicado pela REBEP em $2007^{1}$. Seria complicado para mim tentar resumir uma trajetória destas com base à memória pessoal, especialmente quando está claro que o meu 'disco duro' já apresenta falhas! O fato de ser parte desta história também abre grandes probabilidades de seletividade e viés. Além disso, existe um hiato importante na minha participação nestes debates por conta de longo período em que estive trabalhando no exterior. Mas vou tentar oferecer uma visão pessoal desta trajetória, com desculpas antecipadas a todas e todos pelas falhas.

Na minha visão, as origens do interesse da demografia brasileira na questão ambiental têm duas principais vertentes, cada uma com as suas personagens. Por um lado, despontou graças a uma pesquisa de grande porte encomendada pela Superintendência para o Desenvolvimento da Amazônia

\footnotetext{
${ }^{1}$ MARANDOLA JR., E.; HOGAN, D. J. Em direção a uma demografia ambiental? Avaliação e tendências dos estudos de População e Ambiente no Brasil. Revista Brasileira de Estudos de População, v. 24, n. 2, p. 191-223, 2007.
} 
(SUDAM) ao Centro de Desenvolvimento e Planejamento Regional de Minas Gerais (Cedeplar), ainda na década de 1970. Por conta deste financiamento, o Cedeplar teve estímulos e recursos para contratar quatro pesquisadores de peso (Charles Wood, Marianne Schmink, Diana e Donald Sawyer) para apoiar uma série de estudos demográficos na Amazônia ${ }^{2}$. Aproveitando o embalo, um contingente considerável de professores e alunos do Cedeplar acabaram se interessando pelos temas amazônicos e chegaram a ser, por sua vez, pesquisadores importantes neles. Embora não fossem essencialmente 'ambientais' por natureza no início, estes estudos amazônicos tiveram de abordar necessariamente várias questões adjacentes ao tema. Na medida em que a região amazônica foi se transformando em eixo da preocupação ambiental mundial, a aproximação destas pesquisas com as questões ecológicas ficou ainda mais direta.

Na outra vertente, considero que Daniel Hogan também teve um papel importante na internalização de preocupações ambientais mais genéricas para a comunidade demográfica do Brasil, durante a década de 1980. Recorda-se que o mundo estava começando a ficar atormentado com a confirmação de uma relação estreita entre 'desenvolvimento' e degradação ambiental. Diversos fatores - a constatação do incremento na poluição ambiental mundial, a descoberta de um buraco na camada de ozônio, e as sequelas da chuva ácida nos grandes centros urbanos dos países desenvolvidos - vieram a se juntar às preocupações anteriores referentes à 'conservação' da natureza para provocar um debate crítico sobre as perspectivas da sustentabilidade. Este

\footnotetext{
2 Às vezes brinco que a minha maior contribuição aos estudos amazônicos (e ao Cedeplar) foi a de ter feito uma aproximação entre a SUDAM e o Cedeplar e de ter ajudado a definir um grande projeto de pesquisas migratórias a ser executado na região amazônica pelo Centro (que até então não tinha nenhuma expertise na Amazônia). Isto ocorreu na época em que eu assessorava o Programa de Migrações no Minter. Aos poucos, esta parceria Cedeplar/ SUDAM foi se estendendo a outros temas e nutriu uma grande variedade de estudos.
} 
inspiraria uma acentuação da consciência ambiental internacional, a publicação do relatório Brundtland sobre 'desenvolvimento sustentável' e a própria realização da Rio-92.

Para muitos de nós da comunidade abepiana, na década de 1980, esses temas eram ainda vistos como coisa de país rico e de relevância menor para nossa realidade. Estávamos mais intrigados com outros temas como a descoberta da queda imprevista da fecundidade no Brasil, as implicações sociais dos problemas gerados pela 'década perdida', a luta pelo fim da ditadura militar e as pedras no caminho da redemocratização. Mesmo assim, Hogan conseguiu, aos poucos, instalar as preocupações ambientais mais amplas no cerne das questões substantivas do Núcleo de Estudos de População (NEPO) e da ABEP, montando uma pequena equipe de alunos e pesquisadores voltada para uma visão ampla desses temas ${ }^{3}$. Estas iniciativas, por sua vez, repercutiram na agenda da comunidade demográfica nacional.

Ou seja, no meu entender, os dois principais centros de estudos demográficos brasileiros tiveram, por caminhos diferentes, um papel importante na criação das condições institucionais para o desenvolvimento de estudos ambientais na demografia brasileira.

Ao fazer o relato dessa trajetória, é preciso observar que a internalização desses temas tipicamente ambientais na nossa comunidade foi também marcada pela ideologia dominante e pelas preocupações tradicionais da comunidade abepiana. Esta, além de apresentar uma competência já reconhecida internacionalmente no campo dos estudos populacionais, sempre esteve muito engajada em lutas políticas e sociais, desde sua criação. Uma das características marcantes da $\mathrm{ABEP}$, nestes primórdios, era a sua luta contra o neomalthusianismo que prevalecia no 'establishment' populacional mundial. Tal oposição ao establishment pode ser vista em retrospecto como corajosa ou irônica, tendo em vista que

\footnotetext{
${ }^{3}$ Para uma discussão deste legado, ver: MARANDOLA JR., E.; OJIMA, R. Prefácio. In. HOGAN, D. J.; MARANDOLA JR., E.; OJIMA, R. População e ambiente: desafios à sustentabilidade. São Paulo, SP: Blucher, 2010.
} 
este tinha sido responsável, em parte, pelo próprio florescimento da demografia no Brasil ${ }^{4}$.

De qualquer forma, o ponto é que, ao surgir a discussão ambiental no Brasil, ela foi imediatamente canalizada, em parte, para uma vertente bem específica do debate internacional sobre o tema - ou seja, o papel que o crescimento populacional estaria tendo na acentuação dos problemas ambientais. Quer dizer, a preocupação ambiental nascente não podia se desassociar de questões mais amplas sendo discutidas no seio da ABEP. A nossa literatura inicial sobre população e meio ambiente navegava nessas águas turvas com muito cuidado. O próprio Hogan se viu obrigado a explicar sua posição sobre esses temas em vários artigos no início de sua carreira como ambientalista ${ }^{5}$. Sem embargo, vistos em retrospecto, tanto estes como os trabalhos de outros autores pioneiros da nossa comunidade refletem posturas bastante equilibradas, rejeitando simplismos de lado a lado e chamando a atenção, tanto para a importância, como para a complexidade da influência demográfica.

Revista Idéias: Seria possível dizer que se desenvolveu no Brasil uma visão própria, de algum modo diferente daquela tida em países desenvolvidos sobre questões similares? Conseguimos avançar substancialmente em termos de desenvolvimento de novas teorias e metodologias de abordagem da relação População e Ambiente?

\footnotetext{
${ }^{4}$ A este respeito, ver: MARTINE, G. O papel dos organismos internacionais na evolução dos estudos populacionais no Brasil: notas preliminares. Revista Brasileira de Estudos de População, v. 22, n. 2, p. 257-75, 2005.

${ }^{5}$ Ver as seguintes referências:

HOGAN, D. J. Dinâmica demográfica e poluição ambiental. Textos NEPO, n. 12. Núcleo de Estudos de População, Universidade Estadual de Campinas. Campinas, SP, 1987.

HOGAN, D. J. População e Meio Ambiente. Textos NEPO, n. 16. Núcleo de Estudos de População, Universidade Estadual de Campinas. Campinas, SP, 1989.

HOGAN, D. J. Crescimento demográfico e meio ambiente. Revista Brasileira de Estudos de População, v. 8, n. 1/2, p. 61-71, 1991.
} 
George Martine: Acho fascinante, mas complicada, a tentativa de identificar a origem das ideias e sua evolução. Como ocorre com outros pesquisadores, tenho sido surpreendido ao encontrar conceitos ou noções, que eu pensava ter 'inventado', nos trabalhos de outras pessoas. Mas, para dizer a verdade, eu também teria receio de atribuir a origem das minhas próprias 'invenções' exclusivamente à minha imaginação. Na era dos computadores, está ficando ainda mais difícil identificar especificidades ou visões próprias no pensamento acadêmico, pois as informações e as ideias fluem com muita rapidez entre pesquisadores, centros, comunidades e continentes.

Não tenho certeza se podemos dizer que desenvolvemos novas teorias ou metodologias de abordagem sobre População e Ambiente. Até porque eu não tenho, e nunca tive, muita preocupação com as questões teóricas, epistemológicas ou metodológicas em si. Além disso, é óbvio que tanto o conceito de 'população', como o de 'meio ambiente' cobrem um território enorme. Cada um dos muitos aspectos incluídos nesses dois conceitos amplíssimos pode ser analisado de muitas maneiras e em diferentes níveis de generalidade. Isso transforma o estudo de P/MA num empreendimento multidisciplinar por natureza. Quando percebemos que estas relações entre P/MA são fortemente influenciadas pelos processos de desenvolvimento, a temática fica ainda mais difícil de circunscrever.

O texto de Marandola e Hogan, citado acima, faz um belo esforço para entender as implicações destas características da nossa temática para o avanço do conhecimento científico neste vasto domínio. Como o meu interesse, ao longo dos anos, tem sido mais voltado para o lado das implicações políticas da relação entre população, meio ambiente e desenvolvimento, talvez eu possa tentar identificar a especificidade de algumas posturas políticas da comunidade demográfica brasileira dentro do debate internacional, pelo menos nos primórdios da discussão população/ meio ambiente aqui.

Por exemplo, a postura agressivamente anti-neomalthusiana, marca registrada de grande parte da comunidade abepiana nos 
seus inícios, afetou os primeiros estudos de população e ambiente, no sentido de que todos se sentiam obrigados a tratar do tema. Porém, enquanto o debate internacional enfocava, quase que exclusivamente, a discussão da pressão dos números sobre os recursos naturais escassos, nosso enfoque era mais equilibrado e valorizava mais as outras dimensões da dinâmica demográfica, especialmente a distribuição espacial. Acho que isto, em si mesmo, foi um avanço importante.

Ademais, creio que o nosso grupo avançou algo, tanto na identificação dos temas de maior relevância nacional na relação entre população e meio ambiente, como na explicitação da relação de população e meio ambiente (P/A) com o processo de desenvolvimento $(\mathrm{P} / \mathrm{A} / \mathrm{D})$.

Na época em que foi criado o primeiro GT de meio ambiente na ABEP (em 1990), a discussão ambiental internacional tinha se voltado com intensidade para a questão amazônica. De certa maneira, a necessidade de conservar o enorme valor do 'pulmão amazônico' para a humanidade estava superando a preocupação com os impactos do modelo de desenvolvimento sobre o meio ambiente. Em retrospecto, parece que a discussão internacional - antes da vitória definitiva do neoliberalismo - achava difícil e politicamente complicado enfocar diretamente a relação entre processos de desenvolvimento e questões ambientais. Isso influenciou a concentração das atenções em outros temas importantes, mas subsidiários, como o crescimento demográfico e a devastação amazônica.

Ambos os temas receberam um tratamento diferenciado no nosso caso, conforme eu mesmo destacava nessa época pioneira:

O interesse brasileiro com a questão ambiental é relativamente recente. Talvez por isso, o enfoque, o conteúdo e a escala de preocupações para esta área particularmente no que se refere à região amazônica - ainda refletem as prioridades estabelecidas em outros países. Nesse sentido, o fato de possuir quase um terço da floresta tropical do mundo tem marcado o debate brasileiro sobre a questão ambiental com 
características peculiares e, muitas vezes, distorcidas. Na realidade, o Brasil é hoje um país urbanizado, cuja população é cada vez mais concentrada nas regiões de maior atividade industrial, e cujos problemas sócio-ambientais são cada vez mais decorrentes desta concentração. A agenda ambiental brasileira precisa ser redefinida para poder refletir melhor as preocupações derivadas deste processo mais amplo de transformação econômico e social que vive o país ${ }^{6}$.

O mesmo texto relutava também em aceitar a concentração de interesses nas questões de população versus recursos naturais:

O debate internacional referente ao tema populaçãomeioambientetemenfocado, quasequeexclusivamente, a questão de como o crescimento demográfico impacta o ambiente [...]. Neste ensaio [...] sugerimos que existe uma outra vertente da variável demográfica que poderia ser explorada com mais proveito no caso brasileiro - a distribuição da população sobre o espaço. Embora esta tenha significado estratégico na definição da agenda ambiental brasileira, ela permanece praticamente ignorada na literatura, tanto nacional como internacional?

Na minha avaliação, seria correto dizer que os pesquisadores brasileiros também exerceram um papel importante na explicitação de uma postura mais elaborada dessas questões, ao inserir a discussão população/meio ambiente mais diretamente no contexto concreto do desenvolvimento naquele momento histórico. Neste sentido, a comunidade assumiu uma divergência marcada com a equação dominante, mas simplória, do I = PAT [Impacto humano no ambiente $=$ População $\times$ Afluência $\times$ Tecnologia $]$ com a

\footnotetext{
${ }^{6}$ MARTINE, G. Desenvolvimento, dinâmica demográfica e meio ambiente: repensando a agenda ambiental brasileira. Documento de Trabalho, n. 1. Instituto Sociedade, População e Natureza. Brasília, DF, 1991. (p. 1).

${ }^{7}$ Ibid. (p. 1).
} 
qual Erhlich e Holdren vinham orquestrando a discussão. Ou seja, para nós "desenvolvimento" era, não somente uma coisa muito mais complexa do que a combinação de 'afluência' e 'tecnologia', mas adquiria também uma dimensão de economia política que faltava (e frequentemente continua faltando) nestas discussões. Isto obviamente não quer dizer que outros pesquisadores, em outros âmbitos, não estivessem elaborando pensamentos similares ou até mais pertinentes, mas considero que aqui foram também trilhados alguns caminhos interessantes.

O fato concreto é que, no momento histórico em que se expandiram as discussões sobre meio ambiente e dinâmica demográfica no Brasil, avolumavam-se as evidências da força avassaladora da globalização econômica dirigida pela ideologia do neoliberalismo. Claramente, este processo de globalização estava assumindo um papel dominante na configuração da questão ambiental para o final do século. Vários autores daqui analisaram este fenômeno e apontaram os perigos deste reordenamento da ordem econômica mundial para a sustentabilidade global. Em trabalho seminal, por exemplo, Torres alertava para o efeito da globalização na emergência das indústrias sujas e intensivas em recursos naturais no Brasil ${ }^{8}$. Este foi seguido de outro estudo que analisava os dilemas ambientais que a reordenação econômica representava para os países recentemente industrializados ${ }^{9}$. Por isso, eu escrevia na época que

[...] dois aspectos merecem ser cuidadosamente examinados: primeiro, as contradições entre os paradigmas propostos para o mundo nos âmbitos econômico e mundial: segundo, os reais conflitos de interesses entre grupos e entre nações sobre questões

8 TORRES, H. Emergência das indústrias suja e intensivas em recursos naturais no cenário industrial brasileiro. Documento de Trabalho, n. 9, Instituto Sociedade, População e Natureza, Brasília, DF, 1992.

9 TORRES, H.; MARTINE, G. Reordenação econômica, meio ambiente e urbanização: dilemas da trajetória recente dos NIEs. Documento de Trabalho, n. 20, Instituto Sociedade, População e Natureza, Brasília, DF, 1993. 
que incidem diretamente no futuro ambiental da humanidade $^{10}$.

O nascimento do Grupo de Trabalho sobre meio ambiente, criado no seio da ABEP por iniciativa da então-presidente Neide Patarra, serviu para aprofundar essa discussão. O objetivo do GT era avançar o conhecimento sobre as interações entre meio ambiente e dinâmica demográfica no Brasil, bem como contribuir para políticas públicas adequadas na área ambiental. Tratamos logo de reunir alguns dos pesquisadores que tinham realizado trabalhos sobre o tema ambiental e de discutir uma agenda comum.

Esta busca de uma agenda comum obviamente não foi fácil, dada a amplitude do tema e a variedade de interesses dos pesquisadores. Na minha recordação (obviamente afetada pela 'retenção seletiva'), algumas das discussões mais interessantes giravam em torno da questão de como a globalização e o neoliberalismo afetariam os problemas ambientais no Brasil. A eterna questão neomalthusiana não tinha desaparecido e continuava merecendo ensaios visando esclarecer, tanto para a comunidade acadêmica como para o grande público, a complexidade das interfaces entre população, meio ambiente e desenvolvimento. Mas o que motivava mesmo a discussão era entender como esse mastodonte da globalização ia afetar as relações PAD no caso brasileiro.

Estas discussões desembocaram na publicação do primeiro livro produzido pelo GT em $1993^{11}$. Nele encontravam-se tanto visões amplas de como o contexto mundial afetaria os processos de desenvolvimento e os cenários ambientais, como as implicações destes processos em diferentes âmbitos da realidade nacional.

\footnotetext{
${ }^{10}$ MARTINE, G. Os conflitos inerentes à questão ambiental: O Brasil e a Carta da Terra. Documento de Trabalho, n. 8, Instituto Sociedade, População e Natureza, Brasília, DF, 1991. (p. 1).

${ }^{11}$ MARTINE, G. (Org.). População, meio ambiente e desenvolvimento: verdades e contradições. Campinas, SP: Editora da UNICAMP, 1993.
} 
Com o tempo, o grupo foi incorporando novos interesses dentro da amplitude do tema e também refinando conceitos e abordagens. Um segundo livro, organizado por Torres e Costa e publicado em 2000, evidenciou uma melhor compreensão de vários níveis de complexidade nas relações entre sociedade e natureza. Temas diversos como capacidade de suporte, risco ambiental, qualidade de vida e implicações da urbanização foram abordados e refletiam a busca de uma maior justiça socioespacial e equidade ambiental ${ }^{12}$. Em 2002, foi lançado o livro "Population and Environment in Brazil: Rio + 10" com o objetivo de contribuir para a Conferência de Johannesburgo, levando a perspectiva dos estudiosos brasileiros na área de População e Meio Ambiente ${ }^{13}$. Consta que estes primeiros livros, mostrando um ecletismo crescente, mantêm sua relevância.

A grande guinada do GT nos últimos tempos tem sido no sentido de uma focalização mais explícita na dimensão espacial. Aproveitando interações com outras disciplinas, particularmente a geografia, os estudos e debates da nossa comunidade convergiram progressivamente para destacar a questão espacial. O tema da redistribuição espacial, particularmente em torno da questão da urbanização, tinha sido muito valorizado desde os nossos primeiros estudos como um contraponto importante à discussão neomalthusiana da pressão dos números. Entretanto, a questão espacial passou a ser cada vez mais central agora, fato que resultou num encontro conjunto com o GT de migrações internas, na mudança do nome oficial do nosso GT para "População, Espaço e Meio Ambiente" e na publicação de um número especial da REBEP sobre a questão ambiente e espaço ${ }^{14}$. A utilização crescente

${ }^{12}$ TORRES, H.; COSTA, H. (Org.). População e meio ambiente: debates e desafios. São Paulo, SP: SENAC São Paulo, 2000.

${ }^{13}$ HOGAN, J.; BerQUÓ, E. S.; COSTA, H. S. M (Org.). Population and environment in Brazil: Rio+10. Campinas, SP: CNPD, ABEP, NEPO/UNICAMP, 2002.

${ }^{14}$ Revista Brasileira de Estudos de População, v. 24, n. 2, 2007. 
de novos recursos técnicos como os Sistemas de Informação Geográfica acompanhou e reforçou essa trajetória.

$\mathrm{Na}$ minha perspectiva, como eu sempre insisti na importância da urbanização para a definição das trajetórias econômicas, sociais, demográficas e ambientais dos países "nãoindustrializados", essa virada foi muito positiva. A colocação das relações sociedade-natureza no contexto espacial enriqueceu muito a discussão no grupo, tanto em termos do escopo dos temas como da incorporação de metodologias de investigação. A concentração sobre questões urbanas continua predominando, mas os estudos também enfocam processos de mobilidade em espaços rurais e na ocupação das fronteiras.

Revista Idéias: E hoje, quais são os problemas ambientais que você identifica como de maior relevância? A agenda de pesquisa mudou em que direção? Quais são os temas que você julga serem os mais relevantes daqui em diante no âmbito das discussões sobre população e ambiente no Brasil?

George Martine: Novamente vou responder com meu viés de pessoa engajada e não como pretenso cientista. Quando assumi a presidência da ABEP em 2005, eu falei do alto desta tribuna que eu achava que todos nós, além dos nossos interesses científicos e políticos habituais, deveríamos assumir um compromisso com a questão das mudanças climáticas. Alguns acharam peculiar esta postura, mas os eventos desde aquele momento confirmaram que as questões ambientais - das quais as mudanças climáticas são apenas um elemento mais visível - assumiram uma importância transcendental que nem os mais ferrenhos negacionistas podem desmentir.

A ciência já demonstra, com evidências irrefutáveis, os problemas causados por nosso paradigma de desenvolvimento. Estudos recentes indicam que já ultrapassamos os limites em quatro sistemas planetários e que isto é claramente produto da 
ação humana ${ }^{15}$. Dois destes limites planetários - as mudanças climáticas e a integridade da biosfera - são considerados como "limites fundamentais", pois o agravamento da situação nestas duas fronteiras pode levar a nossa civilização ao colapso. Custa entender como esse tipo de informação, de uma importância crítica para o futuro de toda a humanidade, não consegue penetrar na consciência coletiva da nossa sociedade e, mais ainda, da nossa associação.

Ou seja, no meu entender, a hierarquia e as prioridades para a análise e a ação são bastante claras. Precisamos entender cada vez melhor como e porque estes limites planetários estão sendo infringidos, com que consequências e, mais importante ainda, o que deve ser feito para retardar, e eventualmente reverter, essa caminhada em direção ao caos ecológico. Como já foi explicado por vários analistas como Georgescu e Daly, o problema fundamental surge do caminho adotado pela civilização moderna para a redução da pobreza e o crescimento econômico - o throughput growth - ou seja, a transformação contínua de recursos naturais em dejetos com o objetivo de gerar mais PIB.

Acredito que não seja necessário voltar a discutir aqui todos os problemas que esse caminho para o desenvolvimento acarreta e, ao mesmo tempo, enfrenta. Sugiro apenas que se consultem alguns dos muitos artigos escritos a respeito por nosso colega - e maior articulista brasileiro sobre temas ambientais nestes últimos anos - José Eustáquio Alves, no Boletim Diário Ecodebate. Nesta série, o leitor encontrará uma análise sucinta e acessível de praticamente todas as limitações principais deste nosso processo de desenvolvimento, assim como de suas implicações ambientais.

O grande dilema ético e existencial da humanidade neste século se resume no fato de que o nosso Planeta está sendo seriamente ameaçado pelas ações de uma minoria da população

\footnotetext{
${ }^{15}$ Ver, por exemplo: STEFFEN, W. et al. Planetary boundaries: Guiding human development on a changing planet. Science, v. 347, n. 6223, p. 1259855, 2015. (trabalho de 18 autores do Stockholm Resilience Centre da Universidade de Estocolmo).
} 
mundial, enquanto a maioria ainda espera a expansão do throughput growth para poder sair da pobreza. A minoria defende a continuação de seu estilo de vida, fortemente marcado pela cultura do consumo, enquanto o resto da humanidade está esperançoso de que as instituições que promovem o 'desenvolvimento' consigam lhe estender o privilégio deste mesmo consumo.

O que podemos e devemos estudar para dar uma contribuição efetiva neste terreno crítico? A gama de possibilidades relevantes é quase infinita, e isso nos coloca no mesmo dilema que confrontam os ambientalistas no mundo inteiro: dedicar-se ao tic-tac ou partir para a briga! Ou seja, o ambientalista pode fazer coisas positivas como: a) consumir produtos supostamente menos poluentes (tipo carros elétricos) e fazer coisas corretas como a coleta seletiva de lixo (tornando-se assim mais limpo, mas não mais sustentável, pois essas estratégias individuais não têm um impacto quantitativo relevante no meio ambiente sem a redução do consumo), ou; b) ele pode transformar sua consciência ambiental adquirida através do esforço de 'viver limpo' num engajamento efetivo direcionado para a mudança do paradigma dominante.

Como pesquisadores, podemos também concentrar nossas atenções na variedade infinita dos temas da moda e assim enriquecer nossa relação de publicações acadêmicas, ou podemos tentar entender e explicar como a interação da dinâmica demográfica com os processos de desenvolvimento incide ou é afetada pelas tendências ambientais globais e fazer sistematicamente a ligação entre os conhecimentos específicos e a problemática PAD mais ampla.

A propósito, creio que existem dois filões promissores para esta segunda alternativa, inspirados pela própria debilidade da governança internacional sobre questões ambientais. Por um lado, os relatórios do IPCC, em que pese sua enorme importância, têm escamoteado, em grande parte, a análise sistemática da dinâmica demográfica nas suas projeções. Isto evidentemente reflete a intenção de evitar a paixão política com que ainda se considera questões de reprodução ou de pressões demográficas 
em nível global. Por outro lado, a urbanização tende a ser vista nestes documentos com uma visão negativa simplória. Atualizar esses conceitos e preencher essas brechas pode ser um exercício extremamente interessante.

Outro filão, mais prático ainda, diz respeito aos novos Objetivos do Desenvolvimento Sustentável. Estes foram apresentados pelo Secretário Geral da ONU como "O caminho para a dignidade até 2030: acabando com a pobreza, transformando todas as vidas e protegendo o planeta". Na realidade, os ODS são sujeitos a críticas profundas em cada um dos seus 17 objetivos. No conjunto, os ODS representam a vitória de um modelo altamente insustentável, camuflado de 'desenvolvimento sustentável'. É importante que os pesquisadores analisem detalhadamente a relevância e a efetividade de cada um destes objetivos, seja em nível local ou global, para acabar com as ilusões e conduzir o debate para terrenos mais úteis.

Acredito que se avaliarmos o poder maciço das forças que se unem para conjugar, impor e defender o atual modelo de desenvolvimento, chegaremos à conclusão de que a atual trajetória ambiental só poderá ser alterada por uma mudança radical de valores. Esta poderia ocorrer por decisões políticas impostas por vontade de uma sociedade mais consciente (perspectiva tão remota que nem a ONU se arrisca a propô-la), ou pela acumulação de desastres 'naturais' cada vez mais frequentes e violentos. Para dizer a verdade, acredito mais nesta segunda alternativa; a minha dúvida é se isso vai ocorrer antes ou depois de termos transgredido alguns 'limites fundamentais'.

Neste cenário, me parece que uma vertente central para a pesquisa consistiria na análise de como as tendências da dinâmica demográfica afetam a economia política da cultura do consumo e suas consequências concretas, com o objetivo de fomentar atitudes e movimentos sociais capazes de mobilizar a sociedade numa direção diferente e alterar o pensamento econômico dominante. $\mathrm{O}$ nosso pioneiro neste ramo de pesquisa foi Donald 
Sawyer, que abriu uma série de pistas importantes para a reflexão ${ }^{16}$. Mas, essa vertente crítica só foi retomada na nossa comunidade mais recentemente, e de forma ainda tímida e parcial. Considero, portanto, que precisaríamos ampliar o escopo e aprofundar diversos aspectos do enfoque sobre 'desenvolvimento' na análise das relações PAD.

Revista Idéias: Qual é a sua leitura sobre o momento atual (2014/2015) em que a maioria das regiões do país apresenta chuvas muito abaixo da média, colocando em risco a segurança hídrica e energética da população? Estaríamos atravessando a maior crise ambiental já vivenciada até então?

George Martine: Todos nós que acompanhamos os estudos sobre mudanças ambientais estamos acostumados a observar variações importantes de temperatura e de eventos climáticos de um ano a outro e de região a outra. Esta grande variabilidade tem até permitido que os céticos questionem a própria mudança climática global ou falassem em "hiato" e desaceleração do aquecimento. Entretanto, a tendência de mais longo prazo é indiscutível. $\mathrm{O}$ ano 2014 foi o mais quente do planeta desde o início das medições oficiais em 1880; 14 dos 15 anos mais quentes ocorreram a partir da virada do milênio e o aquecimento está se acelerando, assim como a frequência e a violência de eventos climáticos extremos.

${ }^{16}$ SAWYER, D. População, meio ambiente e desenvolvimento no Brasil. Instituto Sociedade, População e Natureza, Brasília, DF, 1993. Trabalho apresentado no seminário sobre Políticas Públicas, Agentes Sociais e Desenvolvimento Sustentável. Belo Horizonte, 14-15 de junho.

SAWYER, D. Consumption patterns and environmental impacts in a global socioecosystemic perspective. In. HOGAN, D. J (Org). Human Dimensions of Global Environmental Change. Rio de Janeiro, Academia Brasileira de Ciências, 2001.

SAWYER, D. Population and Sustainable consumption in Brazil. In. HOGAN, J.; BERQUÓ, E. S.; COSTA, H. S. M (Org.). Population and environment in Brazil: Rio+10. Campinas, SP: CNPD, ABEP, NEPO/UNICAMP, 2002. 
Vista a questão nestes termos, parece óbvio que estamos entrando (ou atravessando) num segmento particularmente ruim da trajetória climática. A primeira tarefa que nos cabe, portanto, é de analisar o porquê de isto estar ocorrendo, que consequências surgem daí e o que se pode fazer para evitar o agravamento desta situação e reduzir seus prejuízos.

Mas, por outro lado, é preciso evitar também que se atribuam todos os problemas enfrentados por diferentes regiões brasileiras, seja em termos de enchentes urbanas ou crises hídricas, diretamente às mudanças climáticas. As crises atuais refletem também uma tremenda falta de governança e trazem à tona a insuficiência e a vulnerabilidade de todo um modelo de organização da economia, do território e de recursos hídricos. Por último, representa a consequência inevitável de um processo de desenvolvimento que degrada a natureza e destrói metodicamente os ecossistemas.

E preciso recordar que o problema atual tem muito a ver com as políticas governamentais que permitiram a ocupação desregrada e a expansão da pecuária na Amazônia, assim como a monocultura em grandes extensões no Centro-Oeste. Esta combinação é responsável tanto pela redução das chuvas como pela secagem do berço das águas, os aquíferos do Cerrado.

A má gestão do uso do solo também caracterizou a ocupação urbana. Ao longo do tempo, o território urbano e seus entornos foram desmatados, desmembrados e ocupados de acordo com a conjugação de interesses especulativos e desmandos políticos. Entre outras coisas, isto fez com que com o grupo social mais numeroso - os pobres - fosse se estabelecendo, ao longo do tempo, nas piores e mais perigosas localidades. Estas localidades incluem frequentemente áreas de risco, nascentes, áreas ricas em biodiversidade, ou áreas protegidas, agravando assim os estragos feitos pela especulação imobiliária e pela invasão dos mesmos territórios por classes mais abastadas.

Do ponto de vista técnico, os problemas atuais já eram previsíveis. Em 2011, a Agência Nacional de Águas (ANA) publicou um relatório dizendo que, em 2015, haveria problemas de abastecimento em mais da metade dos municípios brasileiros, 
incluindo São Paulo ${ }^{17}$. O que está ocorrendo hoje também foi previsto num trabalho da Secretaria Estadual de Meio Ambiente realizado em $2009^{18}$. Este já projetava dificuldades no sistema Cantareira, assim como conflitos pelo uso de recursos hídricos entre municípios. Esses alertas e planos técnicos foram simplesmente ignorados pelos governantes. A ganância, a irresponsabilidade e a incompetência transformaram eventos ainda 'naturais' em cataclismos sociais.

Portanto, existem diversos níveis de responsabilidade política na questão climática. Estas experiências precisam ser analisadas, historiadas e difundidas para um grande público para impedir a repetição de tais eventos. A tecnologia disponível em termos de mapeamento espacial facilita a reconstituição de padrões de ocupação e a revelação das culpas e omissões.

Um outro lado da moeda que precisa ser analisado e projetado diz respeito aos prováveis impactos das mudanças climáticas sobre diferentes territórios e grupos sociais. As questões referentes à produção e ao uso do espaço, aos desequilíbrios habitacionais, aos entraves à mobilidade urbana, à invasão de ecossistemas por atividades especulativas, à segregação socioespacial urbana, à espacialização de riscos, à documentação de desastres 'naturais' tudo isso continua fornecendo material básico de pesquisa voltada para o esclarecimento do público e, consequentemente, para a reformulação de políticas públicas. Estas temáticas já são objeto de estudos importantes na nossa comunidade.

Revista Idéias: Diante deste cenário complexo para o Brasil em termos de problemas ambientais e suas decorrências sobre a qualidade de vida da população, quais são as saídas que você vislumbra?

${ }^{17}$ ECODEBATE CIDADANIA \& MEIO AMBIENTE. Crise hídrica e falta de governança: sintomas de um problema crônico do Brasil. Entrevista com Eduardo Assad. 9 mar. 2015. Disponível em: http://goo.gl/eOrgVk. Acesso em abril 2015.

18 ESTADÃO. Estado de SP já previa desabastecimento em estudo de 2009. Disponível em: http://goo.gl/bWDZeC. Acesso em abril 2015. 
George Martine: Estou tentado a responder - "Cumbica e Galeão!" - mas eu não sei para onde viajaríamos, pois não vejo solução fácil em lugar nenhum da Terra. Seja em nível global, seja em nível local, a situação exige mudanças de valores e de ações. Vai ser necessário, globalmente, extirpar a cultura do consumo e substituir o desenvolvimento via crescimento, baseado no uso insustentável de recursos não renováveis e na destruição da diversidade biológica, com objetivos, valores e comportamentos sustentáveis. Convenhamos que isto não é nada fácil pois, como até os ODS estão mostrando - especialmente o ODS \#8, que quer promover o desenvolvimento 'sustentável' via o aumento do PIB - até o sistema das Nações Unidas está corrompido pela ideologia do mercado. A continuidade da acumulação de capital e a geração de riqueza via destruição de recursos naturais constitui o objetivo central que mobiliza o mundo.

Em nível nacional, deveríamos também aproveitar a crise ambiental atual para continuar desvendando suas origens e apontando caminhos diferentes para a estruturação de uma deseconomia crescente. Isto exige uma consciência ambiental sedimentada em evidências e disposta a promover ações políticas consequentes com os fatos. Atualmente, isto não está ocorrendo, obviamente. Temos governos preocupados em mostrar serviço no campo econômico e apostando nos benefícios sociais que o aumento do PIB traria para a população mais pobre no curto prazo (e para os governantes na próxima eleição). As dificuldades concretas encontradas para alcançar essas metas não impedem os diferentes componentes do setor público de tentar eliminar os 'entraves' que as preocupações ambientais estariam representando para os objetivos de desenvolvimento. Consequentemente, enquanto $97 \%$ dos cientistas globais que estudam mudanças climáticas concordam que elas estão acontecendo, de fato, e que elas têm origens antropocêntricas, temos a aprovação de Códigos Florestais insustentáveis e a eliminação do próprio tema de desenvolvimento sustentável na Secretaria de Assuntos Estratégicos da Presidência! Enquanto isso, os Ministérios de Ciências e Tecnologia e de Meio Ambiente se dedicam a demonstrar que as mudanças climáticas 
e os eventos climáticos extremos em curso correspondem aos ciclos normais da natureza. Estes fatos ilustram dramaticamente o caminho que falta a ser percorrido antes de sermos capazes de gerar respostas efetivas às mudanças ambientais em curso.

Revista Idéias: Falando de futuro, quais são os temas que você julga serem os mais relevantes daqui em diante no âmbito das discussões sobre população e ambiente no Brasil?

George Martine: Como eu disse anteriormente, nunca consegui motivar-me por exercícios de ciência pura. Sempre achei apropriada a visão do sociólogo C. Wright Mills de que o cientista social tem a responsabilidade de analisar e tentar influenciar os processos sociais. Este tipo de perspectiva obviamente gera um viés na escolha de temas e objetivos. Neste caso, meu viés vai no sentido de que as nossas pesquisas deveriam contribuir principalmente para uma melhor compreensão de como a dinâmica demográfica incide na acentuação ou redução dos 'drivers' dos problemas ambientais globais e locais, e daí contribuir para um 'advocacy' que estimule ações políticas mais efetivas. Já citei vários caminhos, mas sugiro alguns exemplos adicionais aqui, obviamente sem presumir que isto cubra toda a agenda, ou sugerir que todos devam seguir essas trilhas.

De início, acho muito importante a nova geração de pesquisadores se dispor a questionar o senso comum acumulado e o politicamente correto, tanto na economia como na demografia, e não se submeter à patrulhagem ideológica. Como venho repetindo ao longo desta discussão, é indispensável ir a fundo no questionamento do 'milagre do mercado'. Na área demográfica, também faz falta reavaliar a discussão eterna referente à pressão dos números sobre recursos, à luz do contexto atual. Fiz menção disto na minha fala da abertura da ABEP em 2014 e, consequentemente, escutei comentários de que "o Martine virou controlista." Achei até engraçado, dada a minha trajetória sobre esse tema. Mas o fato é que precisamos voltar a ponderar essa questão à luz de novos fatos. O 'inimigo' hoje não é mais o establishment controlista, que 
perdeu seu ímpeto e sua empáfia depois do Cairo, embora sua proposta continue sendo propagada tontamente como "A Solução" por alguns grupos importantes.

O inimigo maior hoje é a corrida desenfreada do mundo para a economia da insustentabilidade e isso traz nuances importantes para a questão. A trajetória da relação entre economia e meio ambiente em nível global sugere a necessidade de rever o papel da dinâmica demográfica nessa equação. Para início de conversa, fica claro, como sempre, que o controlismo não é uma solução em si porque o problema não é o aumento de população senão o aumento de consumidores dentro da economia globalizada; 'consumidor' e 'pessoa' não são equivalentes nesta equação.

Mas o aumento dos consumidores, dentro do paradigma atual de desenvolvimento, é claramente afetado pelo crescimento populacional ocorrido em gerações anteriores. Ou seja, como o êxito do modelo de consumo se define pela sua capacidade de incluir uma parcela cada vez maior da população no mercado, o número de consumidores/poluidores aumentará, ceteris paribus, com o tamanho da população, nos países que conseguirem o crescimento econômico. Nesse sentido, taxas de crescimento demográfico atuais afetam os números de consumidores e a dimensão total do consumo no futuro e isto não é irrisório, conforme o exemplo da China bem dramatiza.

É fato incontestável que os padrões de produção e consumo insustentáveis dos países desenvolvidos e das elites dos países não desenvolvidos - quase todos com taxas de fecundidade reduzidas - são os responsáveis por terem levado o planeta à beira do abismo ecológico. Entretanto, a situação se agrava com o aumento do consumo no resto do mundo. O número de consumidores vem aumentando assustadoramente em países grandes que, até pouco tempo, tinham taxas de crescimento demográfico elevado. Não se pode negar o direito relativo ao consumo dessas massas, mas o fato inegável é que, maior o número de pessoas nestes países, maior o número dos que teriam direito a esse consumo insustentável.

Costumo dizer que o planejamento familiar não tem efeito retroativo. $\mathrm{O}$ dilema é que já temos, mundialmente, um número 
de pessoas (consumidores ou consumidores-em-potencial) muito maior daquele que pode ser sustentado com um padrão de vida similar, digamos, à classe média do Brasil. O crescimento moderado da população é, sem dúvida, um estímulo importante para o modelo de 'throughput growth' que exige aumentos constantes de produção e consumo. Por isso, já tem até economistas no Brasil apregoando a necessidade de políticas pro-natalistas para garantir a continuação do fluxo de mão de obra e do próprio crescimento do PIB via a transformação de quantidades cada vez maiores de recursos naturais em dejetos. Do ponto de vista ambiental, tal estratégia é obviamente insustentável, pois se a população cresce, toda ela também terá direito ao consumo. Multiplicar esse tipo de estratégia pelo tamanho da população mundial crescente (imaginem se a China revertesse sua política anti-natalista!) significaria simplesmente a acentuação do caos ecológico.

Em suma, creio que vale a pena retomar a discussão de recursos versus população à luz dos desafios mais atuais. Obviamente, sem mudanças na definição do 'desenvolvimento' e dos padrões de consumo embutidos nele, não fará muita diferença se a população global atingir um máximo de oito ou quinze bilhões. Muito antes destes bilhões terem se transformado em consumidores, o caos da insustentabilidade terá se instalado, fazendo renascer algumas das ameaças malthusianas.

Mas se formos otimistas - acreditando que haverá inversão dos valores e padrões de consumo, mudanças tecnológicas fantásticas e reversão do próprio paradigma de desenvolvimento a tempo de evitar a transgressão de limites fundamentais - é óbvio que o número de pessoas que precisarão conviver no novo paradigma do decrescimento econômico será um fator crucial.

Em termos de pesquisa propriamente dita, creio que a distribuição espacial ainda oferece o campo mais instigante. Mas a discussão do papel da urbanização nos problemas ambientais não pode se circunscrever à observação de que as populações urbanas têm a maior pegada ecológica. As potencialidades enormes da concentração populacional para a sustentabilidade precisam ser reconhecidas e aproveitadas por uma nova governança. 
Revista Idéias: Quais são os grandes desafios que a área ainda não conseguiu superar?

George Martine: O trabalho de Marandola e Hogan, que citei anteriormente, ao fazer uma análise detalhada da pesquisa população/meio ambiente no Brasil, tenta lidar com o fato de que muitos dos nossos trabalhos não têm um claro compromisso com a dinâmica demográfica propriamente dita. Ou seja, lidam com "populações" de maneira inter- e multidisciplinar, mas a maioria não tem uma clara relação com o tal 'núcleo duro' da demografia. Pessoalmente, não vejo isso como um problema, senão como resultado da amplitude do escopo das nossas preocupações sobre PAD e da riqueza trazida pela pesquisa multidisciplinar. Entretanto, creio que precisaríamos enfrentar com mais empenho o desafio principal que citei anteriormente, ou seja, a análise da conexão entre processos demográficos e tendências ambientais globais.

Dentro deste filão, acho que existem algumas temáticas que poderiam ser abordadas com proveito por nossa comunidade. Já citei várias delas no texto acima. Mas acho que vale agregar outros elementos especificamente 'demográficos' ou 'sócio-demográficos'. Até aqui, nossos estudos têm concentrado sua atenção em dois dos três grandes componentes da dinâmica demográfica e, assim mesmo, de forma parcial. Por um lado, ao enfocarmos os temas de crescimento populacional, temos centralizado nossa atenção na variável 'fecundidade', mas dado pouca atenção às questões de morbidade e mortalidade. Alguns dos primeiros estudos ambientais se centraram nestes fatores, mas há uma gama muito rica de questões que deixamos de explorar a fundo em relação a essa temática. Estas vão adquirir cada vez mais relevância na medida em que aumenta o peso dos temas de vulnerabilidade a crises ambientais.

Por outro lado, temos dado pouca atenção ao componente "estrutura e composição" da população e às suas interações com a problemática ambiental no contexto do desenvolvimento atual. Neste particular, existe um campo aberto para analisar como 
os grandes processos sócio-demográficos em curso, tais como o envelhecimento da população, as mudanças nos padrões de sexualidade e reprodução, as transformações na estrutura familiar e domiciliar e outras estão afetando padrões culturais e níveis de consumo.

Ainda neste último componente, eu chamaria a atenção para uma retomada dos estudos sobre a relação entre gênero/ desenvolvimento/ambiente. Na década de 1990, houve uma explosão de trabalhos inspirados no ecofeminismo. Essa literatura lamentava a situação de mulheres como vítimas de mudanças ambientais, mas enfatizava o papel central que elas, por sua condição de mulheres, exerciam ou poderiam exercer na gerência de recursos naturais e de questões ambientais em geral. Essencialmente, esta literatura presumia a existência de atributos inatos às mulheres que favoreciam a sustentabilidade. Entretanto, como esta concepção significava atribuir características sociais à biologia das mulheres, este tipo de argumento afrontava o próprio conceito de gênero. Consequentemente, essa linha de pensamento não perdurou e o tema gênero perdeu ímpeto nos estudos ambientais.

Isto não significa que as interações entre questões de gênero e meio ambiente não sejam críticas, muito pelo contrário. Significa apenas que estas questões precisariam ser retomadas na perspectiva da análise e da informação, e não surgir unicamente de uma perspectiva de militância feminista.

Tenho a impressão de que a literatura internacional tampouco avançou muito na consideração da influência real ou potencial das questões de gênero na temática ambiental. Quando se encontra algo sobre as relações de gênero nesse contexto, tende a ser em referência às questões de saúde reprodutiva e, consequentemente, ao papel que teria o crescimento populacional na problemática ambiental. Esta brecha nos estudos é significativa, não somente do ponto de vista dos estudos de gênero, mas também em vista do papel potencial do movimento feminista na resolução dos grandes problemas ambientais. Questões culturais - e não biológicas - têm se combinado para fazer com que os movimentos de mulheres 
constituam uma força social muito efetiva neste momento histórico. Ao adotar a preocupação ambiental como objeto de militância, estes movimentos podem injetar uma enorme energia no ambientalismo.

Alguém certamente protestará que isto significaria que as mulheres, mais uma vez, seriam incumbidas de mais uma tarefa ingrata. É verdade, mas é preciso também observar que, sem uma conjugação de todas as forças sociais efetivas em torno do objetivo da sustentabilidade, as bandeiras e agendas tradicionais de movimentos unilaterais poderão rapidamente perder sua prioridade ou mesmo seu sentido.

Revista Idéias: Como você entende que poderíamos aprimorar o diálogo entre o conhecimento produzido pela academia e a elaboração de políticas públicas que dizem respeito às dinâmicas da população e do ambiente? Qual importância você atribui a esse diálogo?

George Martine: Acredito que esse diálogo é crucial porque o futuro da humanidade depende de políticas públicas no terreno PAD que sejam baseadas em evidências científicas e não nas demandas do mercado. No meu entender, todos os acadêmicos e técnicos conscientes da gravidade da situação ambiental são obrigados a fazer todo o possível para esclarecer os fatos e ajudar a conscientizar a população a respeito desses fatos. Estamos remando contra a corrente, porque a grande maioria das instituições oficiais está imbricada, no atual momento, na promoção de um paradigma de desenvolvimento que exige o aumento constante do consumo e que promove essa cultura para alcançar este objetivo.

Entretanto, realizar esse diálogo é difícil. Os próprios acadêmicos, por uma questão de sobrevivência diária, estão mais preocupados com a comunicação dentro da própria academia do que com a sociedade ou com a elite política. Ou seja, o acadêmico tem que provar competência com os seus pares para assegurar ou melhorar a sua situação. Consciência social ou ambiental é outra dimensão, uma que não necessariamente faz parte dos termos de referência do seu emprego. 
Mas mesmo dentro da academia, a comunicação é débil. Um trabalho recente nos Estados Unidos apresenta um cenário fundamental, mas desolador, sobre o impacto dos trabalhos científicos $^{19}$. Segundo os dados citados, apenas $10 \%$ dos trabalhos publicados em revistas científicas são lidos por alguém. Na área de humanidades, a situação é pior ainda, pois $82 \%$ dos artigos publicados não são citados nunca e poucos dos citados foram lidos de fato. Ou seja, mesmo dentro da comunidade científica, o impacto de trabalhos científicos é 'minúsculo'. O impacto sobre a formulação de "policy" destes trabalhos é ainda menor, até porque são pouquíssimos $(0,3 \%)$ os trabalhos que, hoje em dia, oferecem recomendações neste sentido. A sugestão do artigo é que, para ter alguma influência política, os pesquisadores precisariam escrever na mídia popular.

Por outro lado, a maioria de nós não sabemos divulgar nossas ideias de forma a sermos lidos e entendidos por um grande público. Na ocasião da Rio+20, lançamos pela ABEP o livro "População e Sustentabilidade na era das mudanças ambientais globais", procurando estabelecer pontes entre a visão acadêmica e a necessidade de informação da sociedade na temática das questões ambientais e demográficas atuais. Era uma oportunidade para esclarecer o público brasileiro a respeito dos maiores problemas que afetam a humanidade neste século. O livro conseguiu apresentar várias questões brasileiras que fazem parte importante desta engrenagem global.

Como editor do livro, tentei influenciar os autores no sentido de escrever seus textos de forma menos hermética, em linguagem comum. Isto, em si mesmo, foi difícil, pois parte de nossa aprendizagem profissional consiste em utilizar o jargão das nossas disciplinas para a comunicação privilegiada com os nossos pares. Acho que acabamos sendo razoavelmente exitosos na tentativa de tornar o texto mais legível por um grande público.

\footnotetext{
${ }^{19}$ BISWAS, A., K.; KIRCHHERR, J. Prof, no one is reading you. The Straits Times. Opinion. 11 abr. 2015. Disponível em: http://goo.gl/OsGOGq. Acesso em abril 2015.
} 
Mas, mesmo com um produto aceitável, não soubemos 'vender' o livro com publicidade e um marketing à altura dos temas que discutimos no livro. Por isso, considero que foi um esforço bem intencionado, mas fracassado.

Em suma, precisamos contribuir para um diálogo que ajude a convencer e mobilizar a sociedade no sentido de querer promover a sustentabilidade, mas precisamos sair da torre de marfim e sujar as mãos para conseguir realizar esse intento.

Revista Idéias: Para finalizar, se pudesse dar uma dica aos jovens pesquisadores, que estão começando agora a estudar os temas ambientais, tanto na área da Demografia quanto em outros campos do conhecimento, qual seria a sua sugestão?

George Martine: Devo reconhecer que eu estou começando a soar como um disco de vinil quebrado, mas eu vou reiterar que, no meu caso pelo menos, o compromisso social e político tem sido mais importante que a qualidade acadêmica do meu trabalho. Creio que é preciso ter paixão para se dedicar ao trabalho e considero que a intenção de contribuir para a melhoria da sociedade é um estímulo mais instigante do que o reconhecimento acadêmico - embora não sejam coisas incompatíveis. Formalizei esse pensamento na minha dissertação de mestrado e penso que ele influenciou minha trajetória profissional.

No contexto atual, não posso imaginar um estímulo mais forte do que a problemática ambiental, pois sem mudanças radicais nesse terreno, o futuro é assustador para as gerações futuras. Meu modelo na comunidade demográfica brasileira é José Eustáquio Alves da Escola Nacional de Ciências Estatísticas (ENCE), pois ele tem combinado os papeis de pesquisador e de comunicador comprometido de maneira brilhante nos últimos oito anos, tanto em termos de abrir um espaço na mídia para a discussão popular de temas demográficos, sociais e ambientais, como na forma de apresentar temas complexos e importantes. Na área econômica, pesquisadores como Ricardo Abramovay e José Eli da Veiga oferecem bons exemplos de como é possível traduzir 
conhecimentos científicos em matéria de mídia. É importante também estabelecer canais de comunicação com jornalistas interessados (como Antônio Gois) que sabem transformar nossos resultados em matéria interessante para o grande público. Creio que este tipo de diálogo comprometido com a sociedade em geral seja a principal forma de ajudar a mudar a atual trajetória inglória da nossa sociedade consumista. Esta tarefa não é fácil, mas absolutamente crítica. 